\title{
Profil Pondok Pesantren Manarul Huda dan Diskusi Wali Santri
}

\author{
Wardianto $^{1}$, Fitri Marisa ${ }^{2}$ \\ Wardianto06@gmail.com, fitrimarisa@widyagama.ac.id \\ Jurusan Teknik Informatika, Universitas Widyagama Malang
}

\begin{abstract}
Pondok Pesantren Manarul Huda has scored cadre program in the da'wah ahlusunah waljama'ah, who has a problem in publications to the public, information about boarding school, information media studies - the study of Islam, a communication medium between the guardians of students. Therefore the aim of this prolific composer's work is devoted to publicize Profile boarding school and web-based Discussion Guardians Pupils with friendly environments in the dissemination of information to the public and guardians of students. The website is a page of information provided using the internet so it can be opened all over the world, when connected to the Internet. In this website is equipped with chat communication for visitors. Based on the results of the discussions and conclusions made against profiling and discussion boarding students at the boarding school trustee Manarul Huda Malang, that the profile boarding school has been created and can be used and can help to boarding school in the publication of the information - information that helps facilitate the boarding school students and community carers
\end{abstract}

Intisari- Pondok Pesantren Manarul Huda memiliki program dalam mencetak kader dakwah ahlusunah waljama'ah, yang memiliki permaslahan dalam mempublikasi ke masyarakat, informasi tentang pondok pesantren, media informasi kajian - kajian islam, wadah komunikasi antara wali santri. Oleh karena itu tujuan penyusun karya pengabdian produktif ini adalah untuk mempublikasikan Profil Pondok Pesantren dan Diskusi Wali Santri berbasis web dengan ramah linkungan dalam penyebaran informasi kepada masyarakat dan wali santri. Website merupakan halaman informasi yang disediakan menggunakan internet sehingga bisa dibuka di seluruh dunia, apabila terkoneksi internet. Dalam website ini di lingkapi dengan chat komunikasi bagi pengunjung website. Berdasarkan hasil dari pembahasan dan kesimpulan yang dilakukan terhadap pembuatan profil pondok pesantren dan diskusi wali santri di pondok pesantren manarul huda Malang, bahwa profil pondok pesantren sudah dibuat dan dapat digunakan serta dapat membantu pondok pesantren dalam pembuplikasi mengenai informasi - informasi pondok pesantren yang membantu memudahkan wali santri dan masyarakat

Kata Kunci-Profil Pondok Pesantren, Diskusi, Web.

\section{PENDAHULUAN}

Semakin berkembangnya teknologi informasi serta semakin tingginya kebutuhan akan informasi dan komunikasi. media informasi yang dapat di akses oleh siapapun, dan dimanapun ini memudahkan masyarakat dalam mengakses informasi, mendorong setiap lembaga ataupun instansi memperbaiki dalam penyebaran informasi. System informasi berbasis web ini dibuat untuk memudahkan masyarakat dalam mencari informasi mengenai pondok pesantren Diharapkan agar memudahkan masyarakat dalam berkomunikasi,dan mencari informasi, agar media sosial diguanakan dengan baik dan tidak disalahgunakan

\section{METODE PENELITIAN}

\section{A. Analisis suatu system berjalan}

menguraikan secara sistematis aktifitas yang terjadi dalam system informasi yang akan dirancang. Dan di bangun di pondok pesantren manarul huda malang yang akan di gambarkan flowchart sebagai berikut

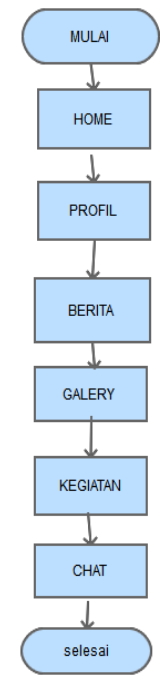

Gambar 1 Flowchart

\section{B. Analisis Kebutuhan Informasi}

Informasi merupakan data yang telah diproses atau di peroleh organisasi kemudian diulang melalui bentuk yng memiliki arti. Berdasarkan analisi terhadap system yang berjalan dan melihat masalah yang ada maka perlunya suatu pemecahan melalui sitem profil pondok pesantren manarul huda malang, yaitu informasi mengenai pondok pesantren yang 
dapat mengakses data dengan mudah, cepat serta mempermudah proses promosi dan informasi.

Dari permaslahan yang tersebut, pondok pesantren manarul huda membutuhkan suatu media informasi yang diharapkan dapat membantu kinerja yang lebih baik dan dapat menghemat tenaga dan waktu. Dengan adanya system informasi ini meliputi beberapa hal yaitu:

1. Informasi publikasi mengenai profil pondok pesantren.

2. Dilengkapi dengan chat agar pengunjung website bisa berkomunikasi

\section{Rancangan Menu Website Pondok Pesantren Manarul Huda}

Sebagai sarana publikasi, pondok pesantren membutuhkan website pondok pesantren yang dirancang dan di bangun dengan konten seperti dibawah ini

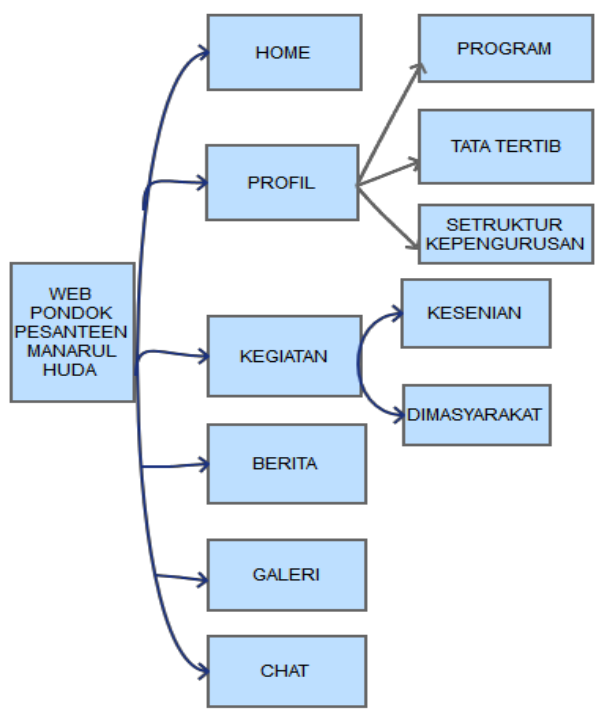

Gambar 2. Rancangan Menu Website

1. Home

Halaman ini merupakan tampilan awal dari website Pondok Pesantren Manarul Huda Malang.

2. Profil

Halaman ini terdiri dari :

- $\quad$ Struktur kepengurusan

- Program

- Tata tertib

3. Kegiatan

Terdapat berbagai macam kegiatan selain belajar mengaji, yaitu:

- Kesenian

4. Berita

Halaman ini merupakan tempat penyampaian informasi bagi pengunjung.

5. Galeri

Halaman ini merupakan berisi tentang dokumentasi kegiatan di pondok pesantren

6. Chat

Halaman chat ini digunakan pengunjung untuk bisa melakukan chat

\section{HASIL DAN PEMBAHASAN}

Website informasi untuk mempermudah mendapatkan informasi. Website ini dibangun dengan ber-hosting pada situs idhostinger.com karena lebih mudah merancang website yang sederhana tapi bermakna.

\section{A. Tampilan Website}

\section{1) Home}

Halaman ini dirancang sebagai halaman awal website Pondok Pesantren Manarul Huda Kota Malang

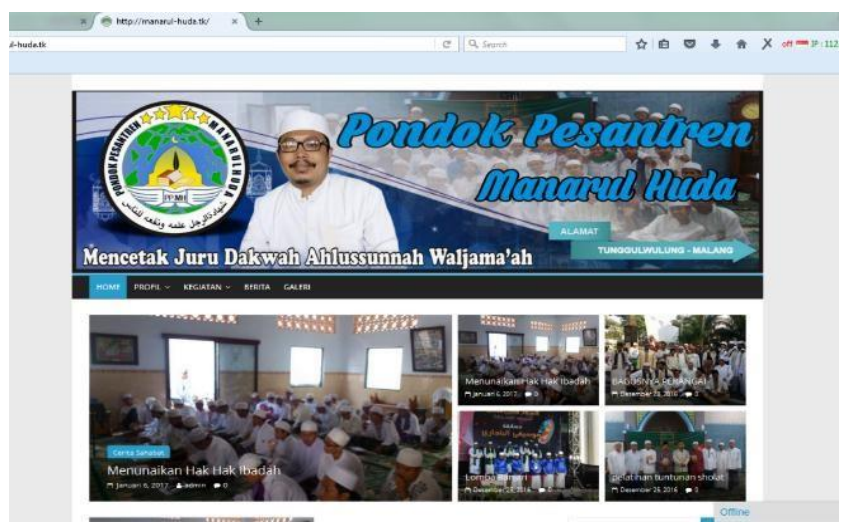

Gambar 3. Tampilan Halaman Home

2) Profil

Halaman ini dirancang untuk diisi informasi mengenai profil Pondok

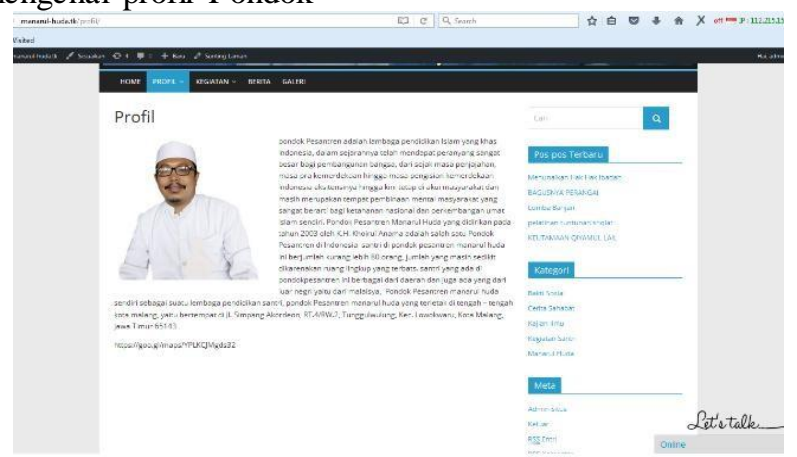

Gambar 4. Tampilan Halaman Profil

3) Kegiatan

Halaman ini berisi kegiatan yang terdapat di pondok pesantren

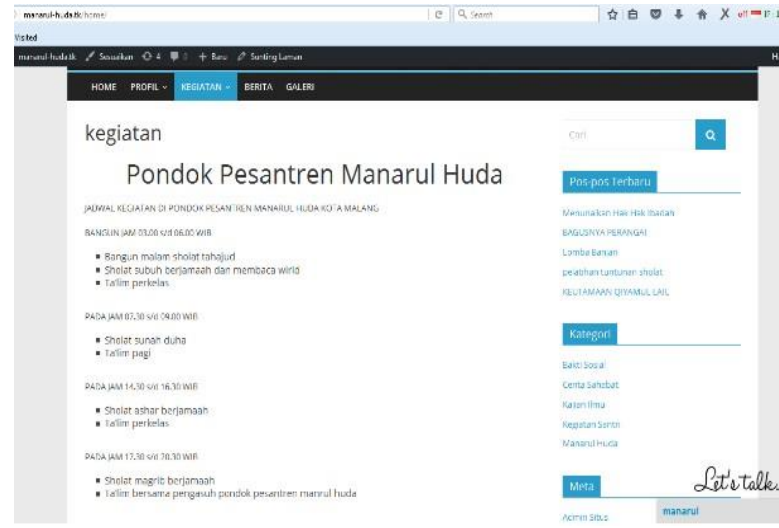

Gambar 5. Halaman Kegiatan 


\section{4) Berita}

Halaman ini akan berisi berita yang berkaitan dengan pondok pesantren

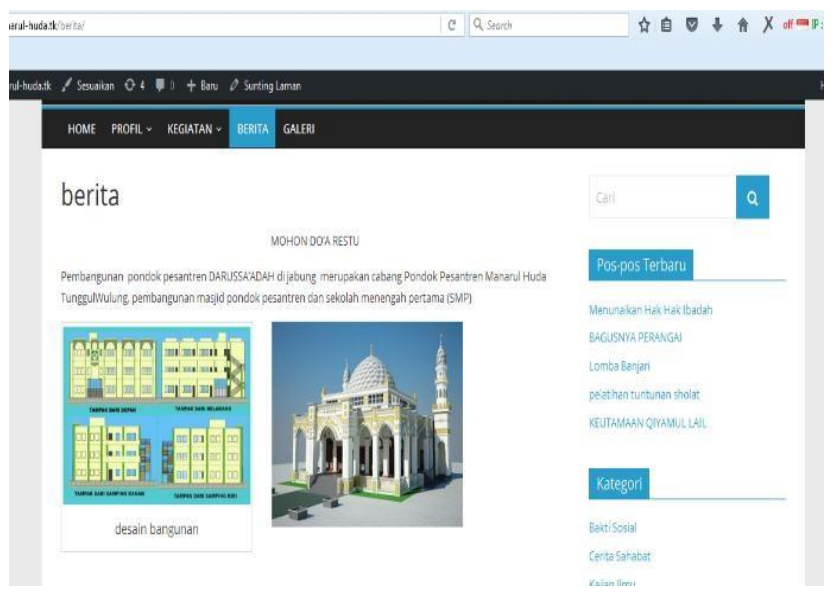

Gambar 6. Halaman Berita

5) Galeri

Halaman ini akan berisi tentang foto - foto mengenai pondok pesantren.

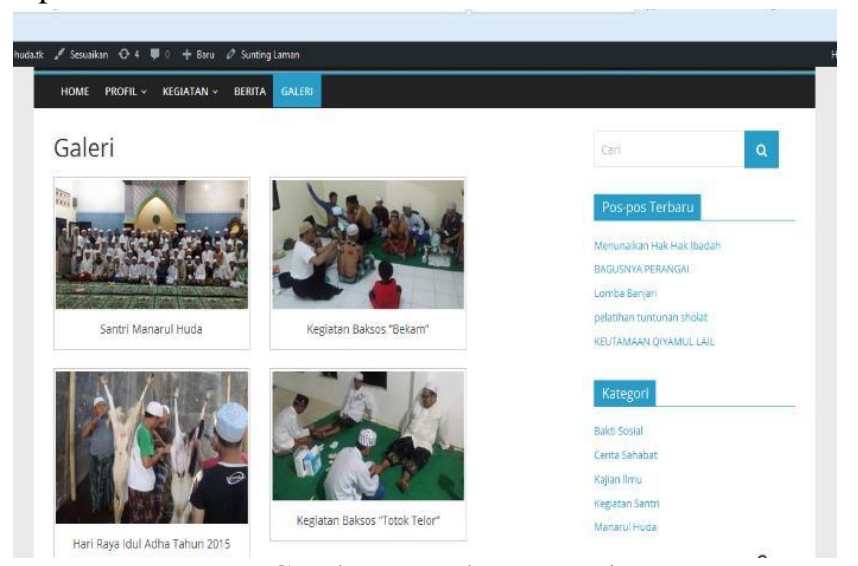

Gambar 7. Halaman Berita

6) Chat Pesan

Pada halaman chat ini akan berisi percakapan pengunjung dengan sesame pengunjung dan admin

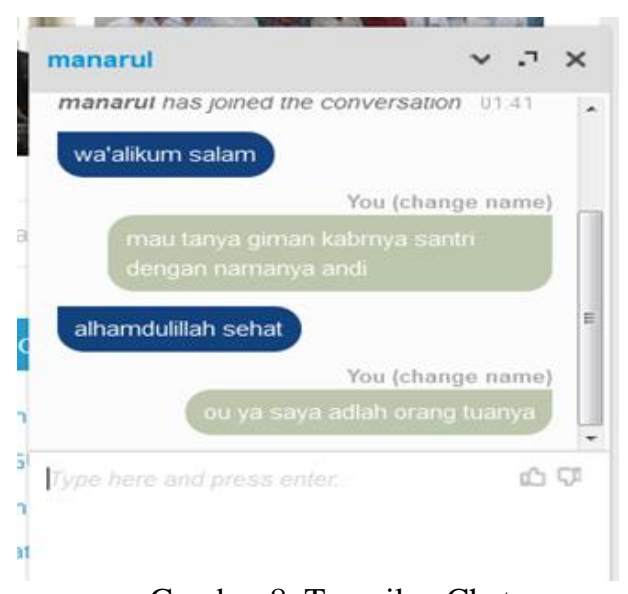

Gambar 8. Tampilan Chat

\section{KESIMPULAN}

A. Kesimpulan

Dari hasil pembahasan website pondok pesantren manarul huda kota malang, penyusun dapat mengambil kesimpulan sebagai berikut :

1. Dalam pembuatan website menggunakan wordpress online dan kemudian dilengkapi dengan chat komunikasi untuk pengunjung website.

2. Informasi yang di dalam website merupakan kegiatan yang terdapat dalam pondok pesantren, dan juga merupakan tempat media dakwah dalam penyampaian kajian - kajian islam berbasis teknolgi

B. Saran

Berdasarkan penyusunan dan pembuatan website ini, akan lebih baik jika website dibangun dengan lebih memperhatikan keindahan desain agar dapat menarik minat pengunjung website. Kemudian, fitur - fitur yang ada dalam website ini dapat dikembangkan lagi

\section{Ucapan Terima kasih}

Terima kasih kami sampaikan kepada pihak Universitas Widyagama Malang yang telah memberikan fasilitas dan dukungan kepada kami di saat melakukan penelitian ini.

\section{Referensi}

[1] ariyani. (2010). ANALISIS PERANCANGAN SISTEM INFORMASI PENERIMAAN SANTRI BARU PADA PONDOK PESANTREN AL-BAROKAH PONCOWARNOKECAMATAN KALIREJO LAMPUNG TENGAH BERBASIS WEB. Jurusan Sistem Informasi, STMIK Pringsewu, Lampung, 3.

[2] Hamid, A. (2015). Nilai-nilai Islam berbasis Pondok Pesantren Optimalisasi Santri dalam Peringatan "HariSantri'. Universitas Islam Negeri Sunan Ampel Surabaya, 13.

[3] Indriyanti, A. D. (2015). PERANCANGAN DAN PEMBUATAN FORUM MAKANAN BERBASIS WEB. Jurnal Manajemen Informatik a, 4, 2.

[4] M, F. A. (2012). POLA KEPEMIMPINAN KYAI DALAM PENDIDIKAN PESANTREN (Penelitian di Pondok Pesantren As-syi'ar Leles). Jurnal Pendidik an Universitas Garut, 6,5.

[5] Pritaningrum, M., \& Wiwin Hendriani. (2013, desember). Penyesuaian Diri Remaja yang Tinggal di Pondok Pesantren Modern Nurul Izzah Gresik Pada Tahun Pertama. Jurnal Psikologi Kepribadian dan Sosial, 2,3 .

[6] Saifudin. (2016). Perancangan Sistem Informasi Pondok Pesantren Berbasis Web Studi Kasus: Darul Abror Watumas Purwokerto. Jurnal Evolusi, 2. 
[7] Shodiq, M. (2011, april). PESANTREN DAN PERUBAHAN SOSIAL. Jurnal Sosiologi Islam, 1, 2.

[8] Sugiyanto. (2013). PEMBUATAN WEBSITE PROFIL SEKOLAH MENENGAH KEJURUAN PEMBANGUNAN NUSANTARA GABUS GROBOGAN. Seminar Riset Unggulan Nasional Informatika dan Komputer FTI UNSA, 3.

[9] Toyibah, M. V., \& Desy Purwanti Kusumaningrum. (2015). SISTEM INFORMASI GEOGRAFIS PONDOK PESANTREN DI KOTA REMBANG BERBASIS ANDROID. Program Studi Teknik Informatika, Fak ultas Ilmu Komputer Universitas Dian Nuswantoro, 4.

[10] Utama, Y. (2011, oktober). SISTEM INFORMASI BERBASIS WEB JURUSAN SISTEM INFORMASI FAKULTAS ILMU KOMPUTER UNIVERSITAS SRIWIJAYA. Jurnal Sistem Informasi, 3, 5. 